\title{
Efficient Use of Satellite Gravity Anomalies for mapping the Great Sumatran Fault in Aceh Province
}

\author{
Muhammad Yanis ${ }^{1 *}$, Marwan $^{1,2}$, and Nazli Ismail1,2 \\ ${ }^{1}$ Department of Geophysical Engineering, Universitas Syiah Kuala, Banda Aceh, Aceh, Indonesia \\ ${ }^{2}$ Department of Physics, Universitas Syiah Kuala, Banda Aceh, Aceh, Indonesia \\ *yanis@unsyiah.ac.id
}

\section{ABSTRACT}

Gravity Satellite has been widely used in tectonic studies and regional of geological mapping. The Satellite Gravity data are provided free by Scripps Institution of Oceanography, University of California San Diego. The data are acquired by GEOSAT and ERS-1 satellites with a $1.5 \mathrm{~km}$ resolution for one pixel. For a further application, the tilt derivative analytic technique was used in order to enhance linear trends of the geological structure revealed by the Bouguer anomalies. The method is represented by the value of an angle between the total horizontal and vertical derivative from the gravity data. The results show that the tilt derivative calculation has been able to map clearly some geological structures on the north of Sumatra i.e., the Aceh and the Seulimeuem segments, as well as some local faults around them. On the other hand, Banda Aceh as the capital city of Aceh Province and Pidie District is dominated by positive values of the tilt derivative anomalies. The data coincide with geological maps of both areas where they are covered by alluvial deposits. Based on the result, it can be concluded that the tilt derivative method is potentially used for quick interpretation of the satellite gravity data.

Keywords: Great Sumatran Fault, Gravity Satellite, Tilt derivative

\section{INTRODUCTION}

The Great Sumatran Fault (GSF) is a strike-slip fault that extends about $1900 \mathrm{~km}$ from Lampung to the Andaman Sea. Such a long fault system splits into 20 segments. At the northern Sumatra, the Great Sumatran Fault scratches into two segments, namely the Aceh and Seulimeuem faults ${ }^{[1]}$. The existence of the fault and seismic gap in the northern Sumatra can potentially cause the seismic hazard to the Aceh region in the future. During the last five years, the seismic activity was recorded that some earthquakes have occurred along the north of the Great Sumatran Fault. For example, Tangse (October 22nd, 2013; 5.6 Mw), Takengon (July 2nd, 2013; 6.2 Mw) and Pidie Jaya (07 December 2016; 6.5 Mw) earthquakes. Even though there is some public infrastructure such as roads, bridges, schools, and archaeological sites that are built in the fault area ${ }^{[2], ~[3] . ~ T h e ~ e v e n t s ~ a r e ~}$ considerably small in magnitudes, but they caused casualties significantly in the areas. Figure 1 shows the seismicity events along the GSF in Northern part of Aceh Province, the data is derived from USGS 1989 - 2019. One of the mitigation efforts for seismic hazards risk reduction is through mapping the active fault.

Geophysical methods have been widely used for fault mapping, for example, in Lamtamot village along the Seulimeuem segment ${ }^{[4]}$, lithological identification on the devastated area of the Pidie Jaya earthquake ${ }^{[5]}$. Furthermore, the geophysical surveys are considerably fast and cost-effectiveness compared to other methods, they are still expensive and time consuming for the regional-scale survey ${ }^{[6]}$. In developing countries with prone to seismic hazards, seeking fast and low fares methods is urgently needed for fault and geological 
mapping. Here we propose to use geophysical open access to gravity satellite data that available on the internet. The gravity method has been widely used for various studies of the fault. For example, ${ }^{[7]}$ has been used the gravity method to map the Shenzhen fault zone. Most of the gravity applications that used ground or airborne measurement are considered an expensive method. Indeed, it is very few papers published using satellite gravity data, due to the low resolution of the data. However, the data set has been used for mapping the basement structures of South China Sea ridge; the gravity anomaly was confirmed to bathymetry data ${ }^{[8]}$. Therefore, it is complicated to perform the direct interpretation of the geological feature from the data sets. In another hand, the 2D, and 3D model of the forward or inverse modeling can produce a better understanding of gravity data, because the data may introduce a non-unique solution. In the research, we used tilt derivative method to enhancement the geological structure in the northern part of the Great Sumatran Fault. The Tilt derivative method is often used to increase the in-direct of geological features, as well as highlight discontinuities features in anomaly trends ${ }^{[9]}$.

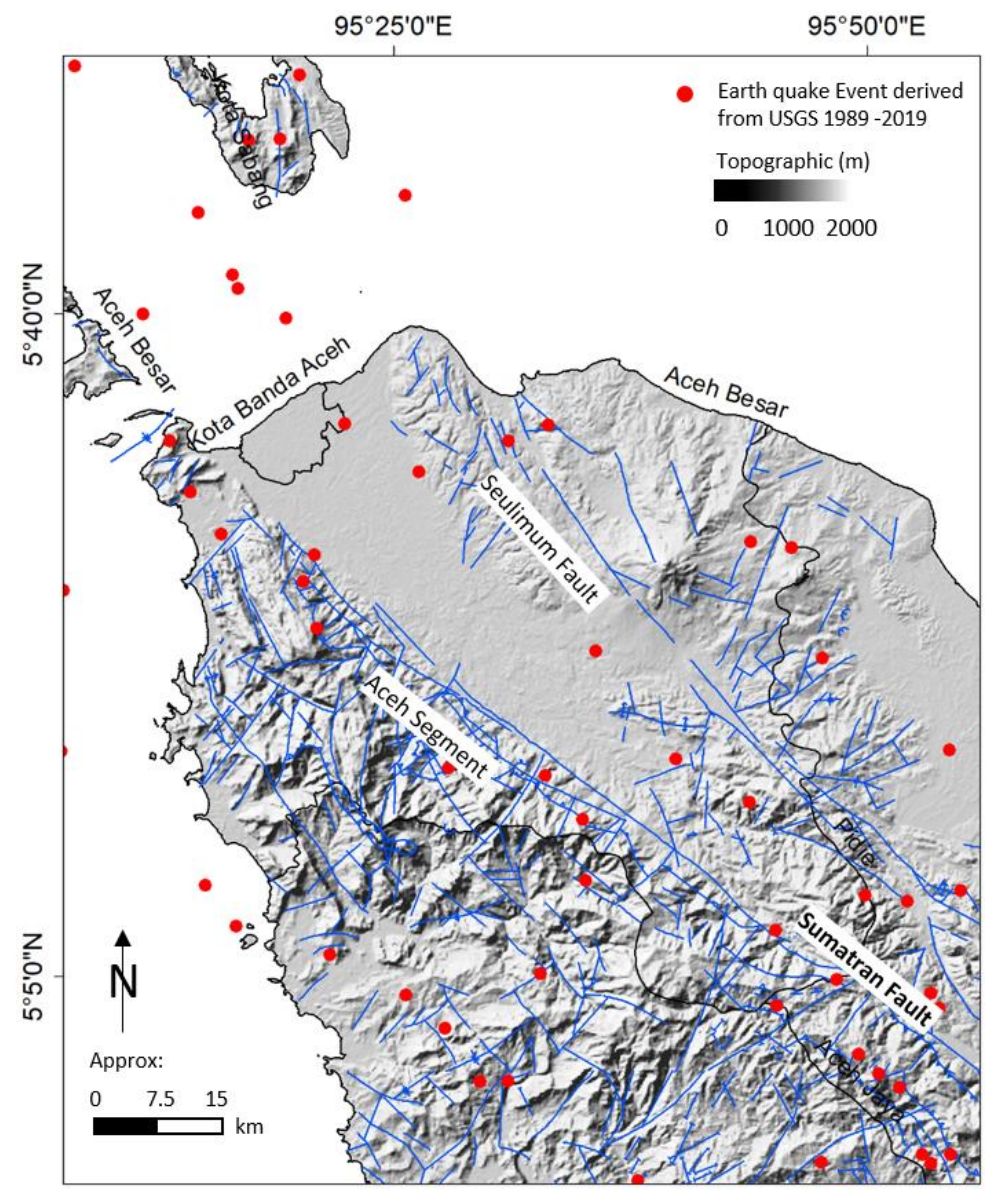

Figure 1. The seismicity events in the Northern part of The GSF from magnitude 1-8 that derived from USGS. For better understanding, the maps also overlaid on the shaded relief (SRTM-90m) and fault structure which is indicated by blue lines

\section{DATA AND METHODOLOGY}

Gravity observed that use in the research is provided from Geosat and ERS-1 satellite with a 1-minute grid. The data have a resolution of $1.5 \mathrm{~km}$ for one pixel. The gravity data obtained from the satellite is free air anomaly. The data is the difference between a theoretical and observed value that has been corrected for the elevation of the data station. 
The free air anomaly data that obtained from satellite survey are used to calculate a Bouguer anomaly with assumed of the density contrast is $2.4 \mathrm{~g} / \mathrm{cm}^{3}$. The gravity anomalies are caused by a lateral density contrasts within associated with a sedimentary section. Figure 1.a shows the Bouguer anomaly data in the area; the map is superimposed with fault structure re-drawn from the geological map. The Bouguer anomalies are in accordance with the geological map of northern Sumatra. High Bouguer anomaly values are dominated in the southwest probably reflected from limestone, while the low Bouguer anomalies are in the northeast because of volcanic rocks dominated in the area. In general, the data have not shown the geological structure of the Great Sumatran Fault yet. All the Bouguer gravity anomaly are positive ranging between 2.48 to $132.8 \mathrm{mGal}$. The Bouguer gravity data are actually connected to the topographical effect of the study area.

In the measurement, the gravity method involves measures the Earth's gravitational field in a specific station to determine the variation of the subsurface density of rocks. The method works when buried objects have different masses from the surrounding material of the research area. One advantage of the gravity method is not only measured on the surface but also in the air. However, the measured gravity data is influenced by factors such as topography, tides, and shape of the earth. All of the factors must be removed before interpreting the subsurface geological features from gravity data. The anomaly contrast of buried feature in the gravity method is the most important step in data interpretation. Edge detection and data enhancement are commonly used in gravity to detect the anomaly of geological structures that can use for quick interpretation for the subsurface explanation, but it still reconfirmed that the anomaly pattern corresponds to the buried structure. For this purpose, the tilt derivative (TDR) has been applied to increase the linear feature of the Sumatran Fault in the subsurface. The method is represented by the value of an angle between the derivatives of total horizontal and vertical from the observed data that can be formulated as;

$$
T D R=\tan ^{-1}\left(\frac{V D R}{T H D R}\right)
$$

Where the VDR value is the vertical derivative from the gravity observed while the THDR is also as a derivative data in part of total horizontal. In similar form, the equation can be re-written as;

$$
T D R=\tan ^{-1}\left(\frac{\partial f / \partial z}{\sqrt{(\partial / \partial x)^{2}+(\partial f / \partial y)^{2}}}\right)
$$

Where $f$ value is the gravity observed data, while the $(\partial \mathrm{f} / \partial \mathrm{x}),(\partial \mathrm{f} / \partial \mathrm{y}),(\partial \mathrm{f} / \partial \mathrm{z})$ symbols are represented by the first derivatives of the observed in the direction of $\mathrm{x}, \mathrm{y}$, and $\mathrm{z}$. The values of TDR range is relatively between $-\pi / 2$ to $+\pi / 2$ in radian. The advantage of the tilt derivative method is well suitable to all source condition of the subsurface; shallow and deep sources. The Tilt derivative maps are also potentially used to recognize the anomaly in the horizontal sources. Figure 2.b illustrations the derivative of a Bouguer data that has been overlaid with the fault map re-drawn from the maps of the geological structure.

Based on the figure, the tilt angle anomaly is the implication response over the geological source in the positive value, while the zero data is represented over or near the source, and negative data is outside from source. This technique is useful for simplicity and quickly detecting between the geological structure and host in the research area. The corrected Bouguer anomalies are then used to construct a tilt derivative maps. Based on the geological maps where anomalies are the located, the pattern of tilt derivative data is most 
likely related to the same geological objects. It can be concluded that the data sets are potentially used for analysis and interpretation of the Great Sumatran Fault.

\section{RESULTS AND DISCUSSION}

Gravity observed is the proceeds of the interruption response over the sources of an anomaly with a different size, densities, and the source of the depth structure. In the potential method (gravity and magnetic), there are most enchantments techniques that can be easy to use for data interpretation. But the advantage of the tilt derivative technique is to map a linear trend that corresponds to many structures, namely faults, geology, and another of the anomaly features. Figure 2 shows the comparison of Bouguer gravity data which has applied the filtering of tilt derivative technique in the northern part of Sumatera fault, i.e., Seulimeuem segment. The Bouguer gravity data (Figure 3.a) that obtained from the satellite has two variations of anomaly value. This anomaly corresponds to the major fault in the Aceh Province. The Seulimeuem segment is possible to map by satellite gravity, but the geology data is needed as support data which is overlaid to compare the fault structure. On another side, the Bouguer data also cannot show the contrast of gravity anomalies which located by geological structure.

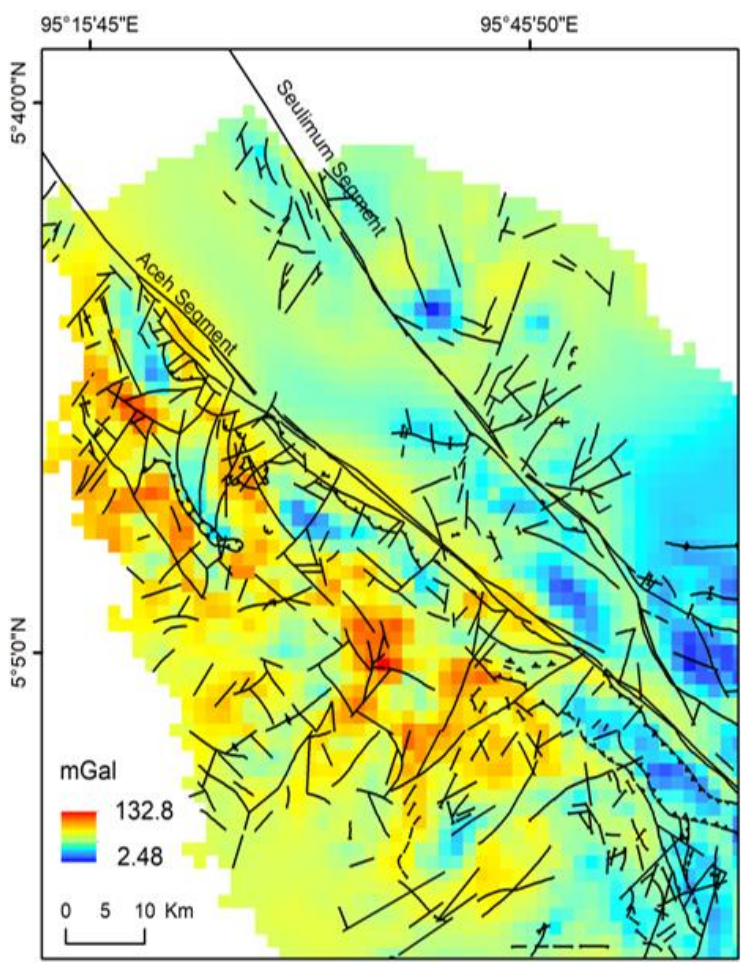

(a)

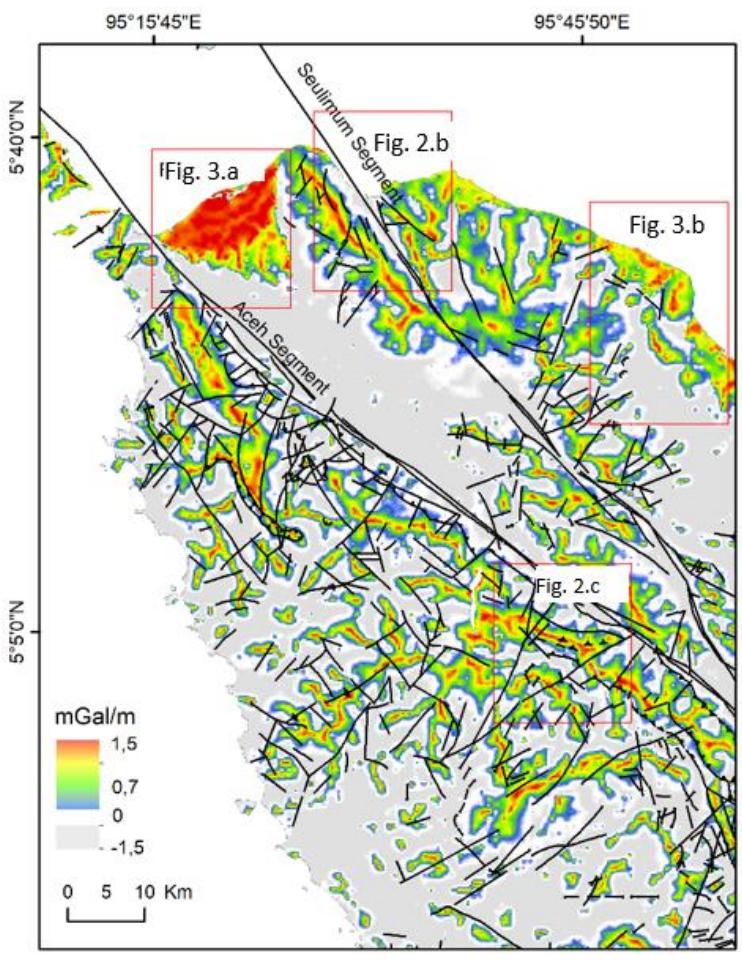

(b)

Figure 2. (a) is a Bouguer anomaly map that overlaid on the fault structure map re-drawn from the geological map of the study area. Faults lineament are shown by black lines, while Fig. (b) Is directional tilt derivatives map of the Bouguer anomaly data. Black lines show faults lineament confirmed from the geological map. The red boxes are further areas study showed in Figure 2 and 3 


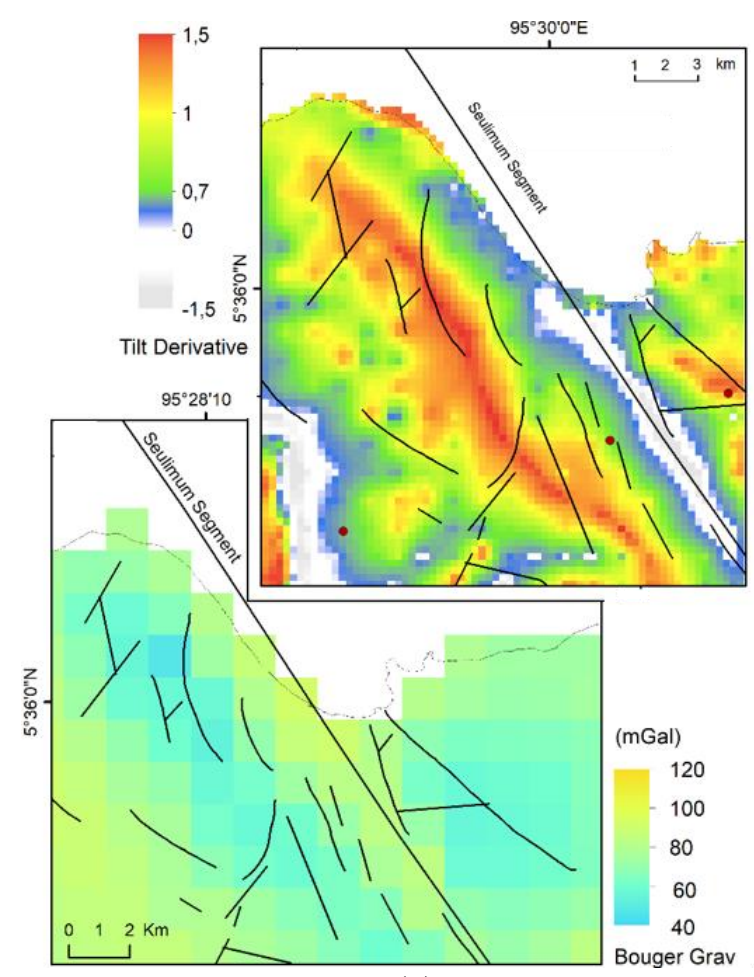

(a)

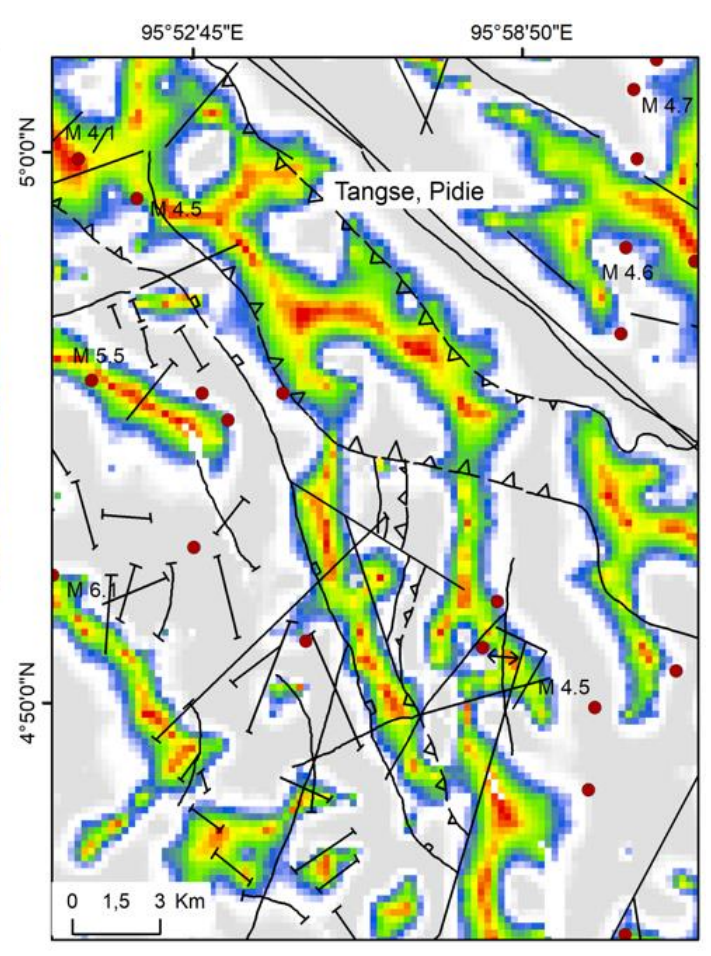

(b)

Figure 3. (a) the different result of Bouguer gravity and tilt derivative data, while Fig. (b) is the minor fault and geological structure that caused the Tangse earthquake with a magnitude above 4 can be precisely mapped based on the lineaments of tilt derivative data

However, the Bouguer gravity satellite data was needed as an enhancement technique to conduct interpretation directly. Figure 3.a present the gravity Bouguer data after filter using tilt derivative. Assuming that the fault is the boundary between the geological structure and other geologies, the edges of the structure or fault traces can be represented by the tilt derivative values of 0 rad. Comparison of geological fault structure and tilt derivative, it will conclude that the data process is concentrated well to many of feature along with the Sumatran faults structure. For a case, the Seulimum segment that extends to the Weh Island can be clearly indicated from the tilt derivative data, and the local fault adjacent to the Seulimum segment can also be mapped accurately.

Tilt derivative technique was not only can map of the geology structure which has a regional characteristic, but also in a minor fault which has the residual anomaly. For example, based on USGS data in Tangse presented the location of earthquake happened with magnitude 6 has caused massive damaged to infrastructure and casualties. However, the tilt derivative data can clearly indicate the alignment structure of fault that correlates with the geological structure (Figure 3.b).

In addition, there is also an earthquake event with a magnitude of less than 4; this indicates that the existence of tectonic activity caused by the fault in Tangse. Moreover, the geology structure minor also can be presented with tilt derivative technique, which has a relatively high value of $0.75-1.5$ $\mathrm{mGal} / \mathrm{m}$. It was indicated as an alignment pattern which has suitable with geology map. In another case, the tilt derivative data is not able to show the alignment structure of minor or major fault in the Seulimum segment. For example; based on USGS data there is some earthquake events accord in Banda Aceh by magnitude 7.0 (Figure 4.a), 


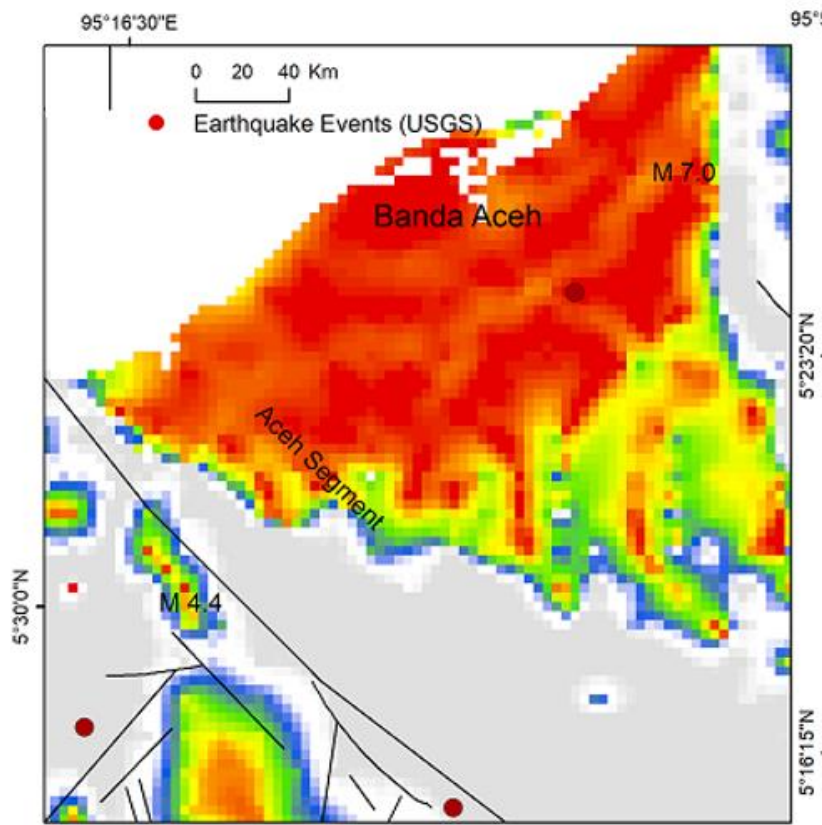

(a)

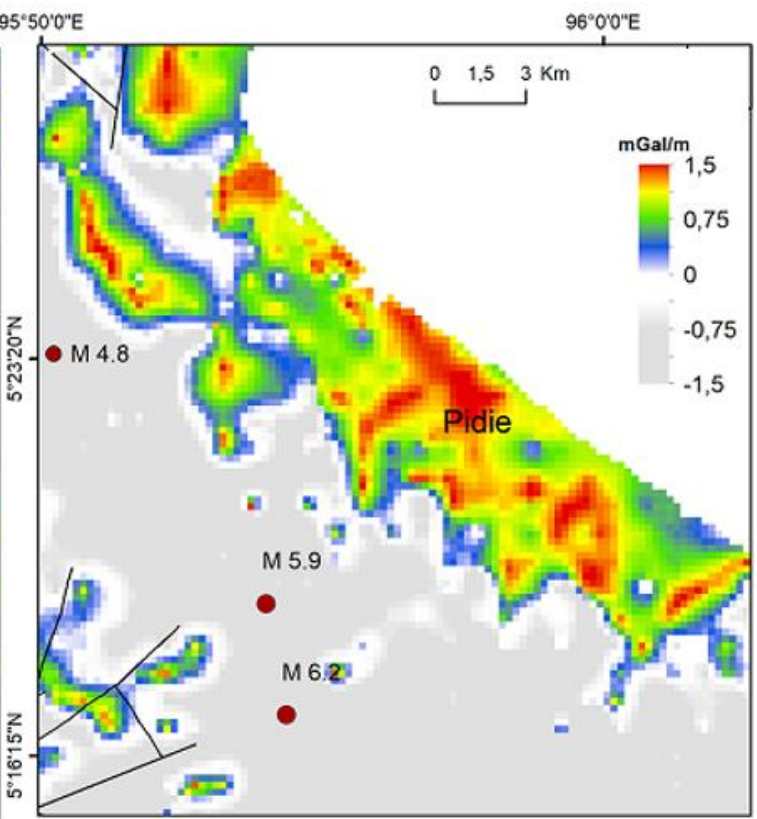

(b)

Figure 4. Tilt derivative data in Banda Aceh and Pidie districts. Based on the geological map, the location was dominated by alluvium rocks. The map also combined with the earthquake data

While magnitude 6.2 and 6.7 that have been accord in Pidie (Figure 4.b). If referring to the geological map, Banda Aceh and Pidie are dominated by alluvium. The alluvium material was clearly seen in Banda Aceh, and Pidie with tilt derivative data was relatively high by $1-1.5 \mathrm{mGal} / \mathrm{m}$ and also the alluvium was shown very dense along with adjacent to the coastal area. So the satellite gravity data is not able to map the fault structure in a location that dominated by alluvium rock. Thus for the mapping of more detailed fault structures at this location, there is a need for nearsurface geophysical measurements.

\section{CONCLUSION}

The research was focused to present a tilt derivative technique as a method for the direction of the gravity satellite interpretation. In general, Gravity radar altimeter mission's data with 1-minute resolution can be used for mapping the alignment structure of the Sumatran Fault, both the Aceh and Seulimum segments. The fault structure can be clearly demonstrated by a tilt derivative value of $0 \mathrm{rad}$. Furthermore, the data could provide useful information on the subsurface structures and other geological information. But in some areas such as Banda Aceh and Pidie that are dominated by alluvium rocks, the regional of gravity satellite is not possible to use. For future work, the gravity ground surveys is recommended as a technique to delineating the fault structure in the region.

\section{REFERENCES}

1 Barber, A. J., Crow, M. J., \& Milsom, J. S. 2005. Sumatera: geology, resource, and tectonic evolution geological society. London

2 Yanis, M., Bakar, M. A., \& Ismail, N. 2017. The use of VLF-EM and electromagnetic induction methods for mapping the ancient fort of Kuta lubok as tsunami heritage i. In 23rd European Meeting of Environmental and Engineering Geophysics

3 Ismail, N., Yanis, M., Abdullah, F., Irfansyam, A., \& Atmojo, B. S. W. 2018. Mapping buried ancient structure using gravity method: A case study from Cot Sidi Abdullah, North Aceh. Journal of Physics: Conference Series 
4 Ismail, N., Yanis, M., Idris, S., Abdullah, F., \& Hanafiah, B. 2017. Near-Surface Fault Structures of the Seulimuem Segment Based on Electrical Resistivity Model. Journal of Physics: Conference Series (Vol. 846). Institute of Physics Publishing

5 Marwan, Asrillah., Yanis, M., \& Furumoto, Y. 2019. Lithological Identification of Devastated Area by Pidie Jaya Earthquake through Poisson's Ratio Analysis. International Journal of Geomate, 17(63)

6 Bürgmann, R. 2018. The geophysics, geology, and mechanics of slow fault slip. Earth and Planetary Science Letters, 495, 112-134

7 Xu, Chuang., Wang, Hai-hong., Luo, Zhi-cai., Ning, Jin-sheng., \& Liu, Hua-Liang. 2015. Multilayer stress from gravity and its tectonic implications in urban active fault zone: A case study in Shenzhen. South China Journal of Applied Geophysics, 114, 174-182

8 Braitenberg, C., Wienecke, S., and Wang, Y. 2006. Basement structures from satellite-derived gravity field: South China Sea ridge, J. Geophys. Res, 111, B05407

9 Eshaghzadeh, A. 2017. Depth estimation using the tilt angle of the gravity field due to the semi-infinite vertical cylindrical source. J. Geol. Res, ID 3513272, 7 